\title{
"Bitlis Hava Kirliliği Emisyon Envanteri ve Sağlık Etkilerinin Çoklu Lineer Regresyonla Tahmini (Doğal Afetler ve Çevre Dergisi, Ocak 2019, 5(1): 1-10)" Başlıklı Makale İçin Başlatılan Tartışmaya Cevap
}

\author{
Sinan Mehmet Turp ${ }^{1, *}$ \\ ${ }^{1}$ Bitlis Eren Üniversitesi, Mühendislik - Mimarlık Fakültesi, Çevre Mühendisliği Bölümü, Bitlis. \\ Özet
}

Bu çalışmada, "Bitlis Hava Kirliliği Emisyon Envanteri ve Sağllk Etkilerinin Çoklu Lineer Regresyonla Tahmini” isimli makaleye tartışma başlatılmış ve yazar, cevap olarak aşağıdaki bilgilere yer vermiştir. Yazar, makalenin yazım aşamasında sadece ithal kömür verilerine ulaşmış ve elde edilen verilere göre hesaplanmalarını ve regresyon analizini yapmıştır. Elde edilen yerli kömür verileri ile kirletici parametrelerden $\mathrm{SO}_{x}, N \mathrm{O}_{x}, \mathrm{CO}$ ve PM $\mathrm{M}_{10}$ emisyon envanterleri ve regresyon analizi tartışma cevabı için tekrar hesaplanmıștır. Makalede birincil kirleticiler ölçülerek değil, hesaplanarak tespit edilmiştir. Bitlis İli Çevre Durum Raporundan alınan verilere göre 2015 yılında, Bitlis iline giris yapan ithal kömür miktarı toplam 55.118 ton ve yerli (Sosyal Yardımlașma Vakfi) kömür 15.000 ton olup, toplam kömür miktarı 70.118 ton'dur. 2015 yılında, yerli kömürden hava kirliliğindeki birincil kirleticilerden $S O_{x}, N O_{x}, P M 10$ ve CO parametreleri sırasıyla, $538 \mathrm{~kg}, 48 \mathrm{~kg}, 57 \mathrm{~kg}$ ve $601 \mathrm{~kg}$ atmosfere deşarj edildiği hesaplanmıştır. 2015 yılına ait Bitlis Sağllk Il Müdürlüğ̈̈'nden alınan solunum ve akciğer hastalıklarından kaynakl hastanelere başvuran hasta saylsı verileri elde edilmiştir. Bu verilere göre klasik çoklu lineer regresyon (ÇLR) yöntemi kullanılarak gelecek yıldaki hasta sayıları tahmin edilmiştir. Gerçek veriler ve tahmin verileri tekrar karşılaştırılarak $R^{2}=0,81$ oranında uyum sağlanmıştır.

\section{Anahtar Sözcükler}

Hava Kirliliği, Emisyon Envanter Hesaplama, Kirleticilerin Sağliksal Etkileri, Çoklu Lineer Regresyon Analizi

\section{Reply to the Discussion Started for the Article Titled as "Bitlis Air Pollution Emission Inventory and Estimation of Health Effects by Multiple Linear Regression (Journal of Natural Hazards and Environment, January 2019, 5(1):1-10)"}

\begin{abstract}
In this study, the author gave the following information in response to the discussion initiated for the article titled "Bitlis Air Pollution Emission Inventory and Estimation of Health Effects by Multiple Linear Regression". In the writing process of the article, the author only obtained the imported coal data and calculated the regression analysis according to the data obtained. SOx, NOx, CO and PM1O emission inventories and regression analysis were recalculated from the pollutant parameters. In the article, primary pollutants are determined by calculation, not by measurement. According to the data obtained from the Bitlis Environmental Status Report, the total amount of imported coal in Bitlis province in 2015 is 55118 tons and the Domestic Coal (Social Assistance Foundation) is 15000 tons and the total coal amount is 70.118 tons. In 2015, SOx, NOx, PM10 and CO parameters of primary pollutants in air pollution from domestic coal were calculated to be discharged to the atmosphere at $538 \mathrm{~kg}, 48 \mathrm{~kg}, 57 \mathrm{~kg}$ and $601 \mathrm{~kg}$, respectively. Number of patients who applied to hospitals due to respiratory and lung diseases obtained from Bitlis Health Provincial Directorate of 2015 were determined. According to these data, classic multiple linear regression method was used to estimate the number of patients in the next year. The real data and the estimation data were compared again to ensure that $R^{2}=0.81$.
\end{abstract}

\section{Keywords}

Air Pollution, Calculation of Emission Inventory, Healthy Effects of Pollutants, Multiple Linear Regression Analysis

\section{Tartışma}

\subsection{Yakıt Miktarları}

Tartışmayı başlatan yazar, kömür miktarları ile ilgili yaptığı yorumda 55.117 ton ithal kömür, 15.000 ton (sosyal yardımlaşma kömürü), $800 \mathrm{~m}^{3}$ fuel oil yakıtı yakıldığı șeklinde bilgi vermiștir. Makalede belirtilen toplam kömür miktarının birimi ile ilgili yazar, tipolojik bir hata yaparak, hesaplamalarını ton birimi olarak yapmış ancak kg olarak makalede yer almıştır. Tartışmayı başlatan yazar bilmelidir ki, hesaplanan veriler ışı̆̆ında sonuçlar değişmemektedir. 
Aynı zamanda çalışmanın yapıldığı tarihlerde yerli kömür tüketim verilerine ulaşılamadığından hesaplamalarda yer verilmemiştir. Ancak Tablo 3 'te yerli kömür miktarları verilmiş olup, tekrar emisyon envanteri oluşturulmuş ve analiz edilmiştir.

Yazar, yapılan çalışmada sadece ithal kömür verisini kullanmıș ve sosyal yardımlaşma verisini kullanmamıș olduğunu makalesinde belirtmiştir. Ayrıca metot kısmında belirtilen emisyon hesaplaması kısmında fuel oil, linyit odun ve benzeri yakıtların dahil edilmediği ve sadece kömür tüketimleri ile ilgili verilere yer verildiğini beyan etmiştir.

\subsection{Alt Isıl Değerlerinin (AID) hesaplanması}

$\mathrm{SO}_{2}$ emisyon faktörünün hesaplanmasında ve tartışmaya bahse konu olan Turp ve Turp (2015)'de belirtildiği gibi \%S ve AID değerleri sırasıyla \%1,2 ve $5731 \mathrm{kcal} / \mathrm{kg}$ olarak kabul edilmiştir. Turp ve Turp (2015), bu verileri Avrupa Çevre Ajansından (EEA 2016) elde etmiş ve bunları Bitlis'te kullanılan kömürün kükürt içeriği ve AID değerlerini tahmin etmek için referans olarak kullanmıştır. Bu bilgilere de referans olarak makalede yer verilmiştir. Turp ve Turp (2015)'de kullanılan \%S ve AID varsayımlarına ve yaklaşımlarına katılmamayı, bilimsel hatalar olarak değerlendirmektedir. Aynı zamanda yazarlar, Bitlis İli Çevre Durum Raporunda (2015) (URL-1 2015) ve Avrupa Çevre Ajans1 (EEA 2016) arasındaki ara değerleri kullanmayı tercih etmiştir. Bitlis İli Çevre Durum Raporunda (2015) belirtilen kömürlerin verilerinin fiziksel ve kimyasal özellikleri açıkça belirtilmemiştir. Kılavuz Kitabında sunulan verilerin de bazı genel varsayımlara dayanarak belirlendiği bilinmektedir. Bir ölçümden veya laboratuvar ölçeğindeki bir testten elde edilen verilerin dışında, yazarlar, elde edilen verilere tam anlamıyla güvenmemeyi veya bu bilgilere dikkatle yaklaşmayı tercih etmişlerdir. Bu nedenle, Turp ve Turp (2015) yayınında EEA (2015) (\%S için \%1.2 ve AID için 5731 kcal/kg) ve Çevre Durum Raporu (URL-1 2015) (\%S için 0.4-0.5\% ve AID için $6800 \mathrm{kcal} / \mathrm{kg}$ ) değerlerinin ortalama değerlerini kullanılmıştır. Tartışma yazarı, bilmelidir ki bu durum konunun doğruluğunu ve genel sonuçlarını önemli bir ölçüde etkilememektedir.

Tablo 1: Ithal ve yerli kömür için emisyon faktörleri

\begin{tabular}{|l|c|c|c|c|}
\cline { 2 - 5 } \multicolumn{1}{c|}{} & \multicolumn{2}{c|}{$\begin{array}{c}\text { İthal Kömür İçin Emisyon } \\
\text { Faktörleri (Kg/Ton) }\end{array}$} & \multicolumn{2}{c|}{$\begin{array}{c}\text { Yerli Kömür İçin Emisyon } \\
\text { Faktörleri (Kg/Ton) }\end{array}$} \\
\hline Kirleticiler & Soba & $\begin{array}{l}\text { Orta boy kazanlar } \\
\mathbf{5 0 ~ k W ~ i l e ~ 1 ~ M W ~ a r a s ı ) ~}\end{array}$ & Soba & $\begin{array}{l}\text { Orta boy kazanlar } \\
\mathbf{5 0 ~ k W ~ i l e ~ 1 ~ M W ~ a r a s ı ) ~}\end{array}$ \\
\hline $\mathrm{SO}_{2}$ & 17.98 & 17.98 & 35.93 & 35.93 \\
\hline $\mathrm{NO}_{2}$ & 2.68 & 4.28 & 2.01 & 3.21 \\
\hline $\mathrm{PM}_{10}$ & 12.04 & 5.08 & 9.03 & 3.81 \\
\hline $\mathrm{CO}$ & 133.76 & 53.50 & 100.32 & 40.13 \\
\hline
\end{tabular}

İthal kömürün sobada yakılması sonucu ortaya çıkan emisyonlarda Tablo 1'de verilen değerlerde tipolojik hatalar mevcut olup doğrusu Tablo 1'de mevcuttur. Yazar, yukarıdaki değerler doğrultusunda hesaplamalarını yapmıştır. Bu tipolojik hatalar makalenin doğruluğunu etkilememektedir.

\subsection{Aylık Kömür Miktarlarının Hesaplanması}

Bitlis ili 2015 yılına ait aylık kömür miktarları ilin 2015 yılına ait hava kalitesi parametrelerinden $\mathrm{SO}_{2}$ 'nin aylık ortalama değerler tablosuna göre hesaplanmıştır. İlimizde Bulunan Hava Kirliliği Ölçüm Cihazının vermiş olduğu değerler toplamı ile kullanılan toplam kömür miktarı değerine orantılanmıştır. $\mathrm{SO}_{2}$ 'nin o ay (Ocak, Şubat, vd.) değerine bölünerek aylık kömür tüketim miktarları hesaplanmıştır. Bu şekilde ay bazında tüketilen kömür miktarları oranlanarak hesaplanmıştır. 2015 Temmuz ayında Bitlis Hava Kalitesi ölçüm cihazının ölçmüş olduğu $\mathrm{SO}_{2}$ verisinin $5 \mu$ gr/m³ 'e yükseldiği görülmektedir (Tablo 2). Bu yükselmeden dolayı aylar bazında kömür tüketimi de yükseldiği hesaplanmıştır.

Tartışmacının belirtmiş olduğu Avrupa Çevre Ajansının Hava Kirletici Emisyon Envanteri Kılavuz Kitabından yararlanıldığı materyal metot kısmında bahsedilmiş olup, evrensel olarak tanınan bilim kuramları, bilim alanlarının temel bilgileri, matematik teoremleri ve ispatları gibi önermeler olduğundan kaynak olarak gösterilmemiştir.

Ayrıca kömür tüketimi, konut sakinleri, kurumlar veya sanayi kuruluşları tarafindan satın alınan toplam kömür miktarının hesaplanmasıyla tahmin edilmektedir. Bu nedenle, "satılan kömür" veya "tüketilen kömür" kullanımı, emisyon envanterinin yanlış hesaplanmasına asla yol açmamaktadır. Gerçekte, bir şehirde yanmış kömürü veya yanmış yakıtı tahmin etmek imkânsızdır. Yazar, her hanenin yanında bulunamayacağından satın alınan kömürlerin yakıldığından asla emin olamaz. Bu sebeplerden dolayı, hava kirliliği araştırmaları genellikle, yıllık kömür tüketimine veya hava kalitesini değerlendirmek için bir şehirde satılan kömür miktarına bağlı olarak değerlendirilmektedir. 
Bitlis Çevre Durum Raporunda Bitlis ilinde 2015 Y1lı Hava Kalitesi Parametreleri Aylık Ortalama Değerleri Tablo 2'de verilmektedir (URL-2 2016).

Tablo 2: Bitlis ilinde 2015 Yılı Hava Kalitesi SO 2 Parametresi Aylık Ortalama Değerleri (havaizleme.gov.tr, 2016)

\begin{tabular}{|c|c|c|c|c|c|c|c|c|c|c|c|c|}
\hline Bitlis & Ocak & Şubat & Mart & Nisan & Mayıs & Haziran & Temmuz & A ğustos & Eylül & Ekim & Kasım & Aralık \\
\hline $\begin{array}{c}\mathbf{S O}_{2} * \\
\left(\boldsymbol{\mu g} / \mathbf{m}^{\mathbf{3}}\right)\end{array}$ & 7 & 10 & 12 & 14 & 6 & 4 & 5 & 4 & 5 & 6 & 22 & 26 \\
\hline
\end{tabular}

* Aylık kömür miktarları Bitlis ilinde 2015 yılı hava kalitesi parametrelerinden $\mathrm{SO}_{2}$ aylık değerlerine göre hesaplanmıştır.

Çalışmanın yapıldığı tarihlerde yerli kömür tüketim verilerinin ulaşılamadığından makaleye eklenememiştir. Ancak daha sonra Çevre Durum Raporunda veriler paylaşıldığı için Tablo 3'te 2015 yılına ait Bitlis'te kullanılan yerli kömür miktarları (ton) detaylıca yazılmıştır.

Tablo 3: 2015 Yılı Bitlis'te kullanılan yerli kömür miktarları (ton)

\begin{tabular}{|c|c|c|c|c|c|c|c|c|c|c|c|c|c|}
\hline Aylar (2015)* & Ocak & Şubat & Mart & Nisan & Mayıs & Haziran & Temmuz & Ağustos & Eylül & Ekim & Kasım & Aralık & $\begin{array}{l}\text { TOPLAM } \\
\text { (ton) }\end{array}$ \\
\hline $\begin{array}{c}\text { Yerli Kömür } \\
\text { Sosyal } \\
\text { Yardımlaşma * } \\
\text { (ton) }\end{array}$ & 867 & 1239 & 1487 & 1735 & 743 & 495 & 619 & 495 & 619 & 743 & 2727 & 3223 & 15000 \\
\hline
\end{tabular}

* Yerli kömür verileri Bitlis ili 2015 Yılı Çevre Durum Raporundan alınmıștır.

EEA'nın Tier-2 yöntemi, emisyon faktörlerinin hesaplanmasında verilere uygun olarak seçilmiştir. Ayrıca IPCC'nin Tier-1 yöntemi ise sera gazı emisyon faktörleri için tercih edilmiştir (Sonsuz vd. 2011). Bitlis ili 2015 y1lına ait aylık kömür miktarları ilin 2015 yılına ait hava kalitesi parametrelerinden $\mathrm{SO}_{2}$ 'nin aylık ortalama değerler tablosuna göre hesaplanmıştır ve regresyon analizine eklenmiştir.

\subsection{Aylık Emisyon Envanterinin Hesaplanması}

Tablo 4: 2015 yılına ait emisyon envanteri (ithal ve Yerli Kömür) (kg/ay)

\begin{tabular}{c|cccc}
$\begin{array}{c}\text { 2015 Yılına Ait } \\
\text { Emisyon Envanteri }\end{array}$ & SOx & NOx & PM10 & CO \\
\hline Ocak & 88.51 & 16.43 & 19.50 & 195.85 \\
Şubat & 126.44 & 23.47 & 27.86 & 279.78 \\
Mart & 151.73 & 28.17 & 33.43 & 335.74 \\
Nisan & 177.02 & 32.86 & 39.00 & 391.70 \\
Mayıs & 75.86 & 14.08 & 16.71 & 167.87 \\
Haziran & 50.57 & 9.39 & 11.14 & 111.91 \\
Temmuz & 63.22 & 11.73 & 13.93 & 139.89 \\
Ăgustos & 50.57 & 9.39 & 11.14 & 111.91 \\
Eylül & 63.22 & 11.73 & 13.93 & 139.89 \\
Ekim & 75.86 & 14.08 & 16.71 & 167.87 \\
Kasım & 278.17 & 51.64 & 61.30 & 615.53 \\
Aralık & 328.75 & 61.03 & 72.44 & 727.45 \\
TOPLAM & $\mathbf{1 5 2 9 . 9 8}$ & $\mathbf{2 8 4 . 0 5}$ & $\mathbf{3 3 7 . 1 5}$ & $\mathbf{3 3 8 5 . 4 4}$ \\
& & & & \\
\hline
\end{tabular}

Atmosfere salınan kirletici miktarının artmasına bağlı olarak soğuk havanın Kasım - Aralık ayında etki gösterdiği söylenebilir. Meteoroloji genel müdürlüğünden alınan verilere göre Bitlis İlinde ortalama en düşük sıcaklık Ekim ayında başlamakta olup, yıl boyunca görülen artışlar ve azalmalar, hava durumu ve sıcaklık farklarına göre değişmektedir. Bitlis iline ait, 2015 yılı atmosfere deşarj edilen ithal ve yerli kömürün aylık kirletici miktarları tekrar hesaplanmış ve Şekil 1 'de belirtilmiştir. 


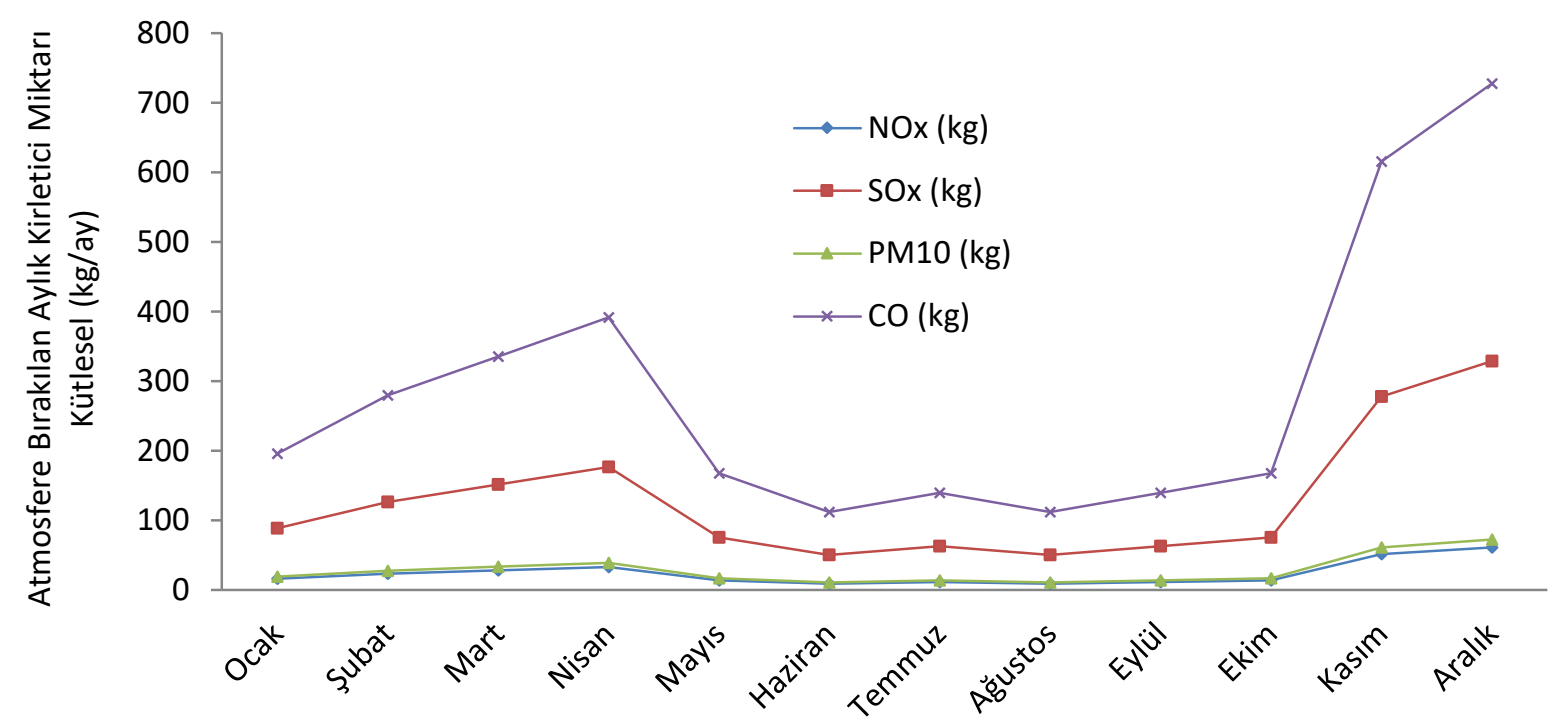

Şekil 1: Bitlis ili 2015 yılında aylara göre birincil kirleticilerin atmosfere dağılımı (Ithal ve Yerli Kömür)

İthal ve yerli kömürün tüketim verilerinden hesaplanan emisyon değerlerinden faydalanılarak ve 2015 yılında solunum ve akciğer rahatsızlıkları nedeniyle Bitlis ilinde merkez ve ilçelerde hastanelere başvuran hasta sayıları çoklu lineer regresyon yöntemiyle tekrar hesaplanmış, gerçek değerlerle tekrar karşılaştırılmış ve $\mathrm{R}^{2}=0.81$ uyum sağlamıştır (Şekil 2).

\section{5 Çoklu Lineer Regrasyon Analizi}

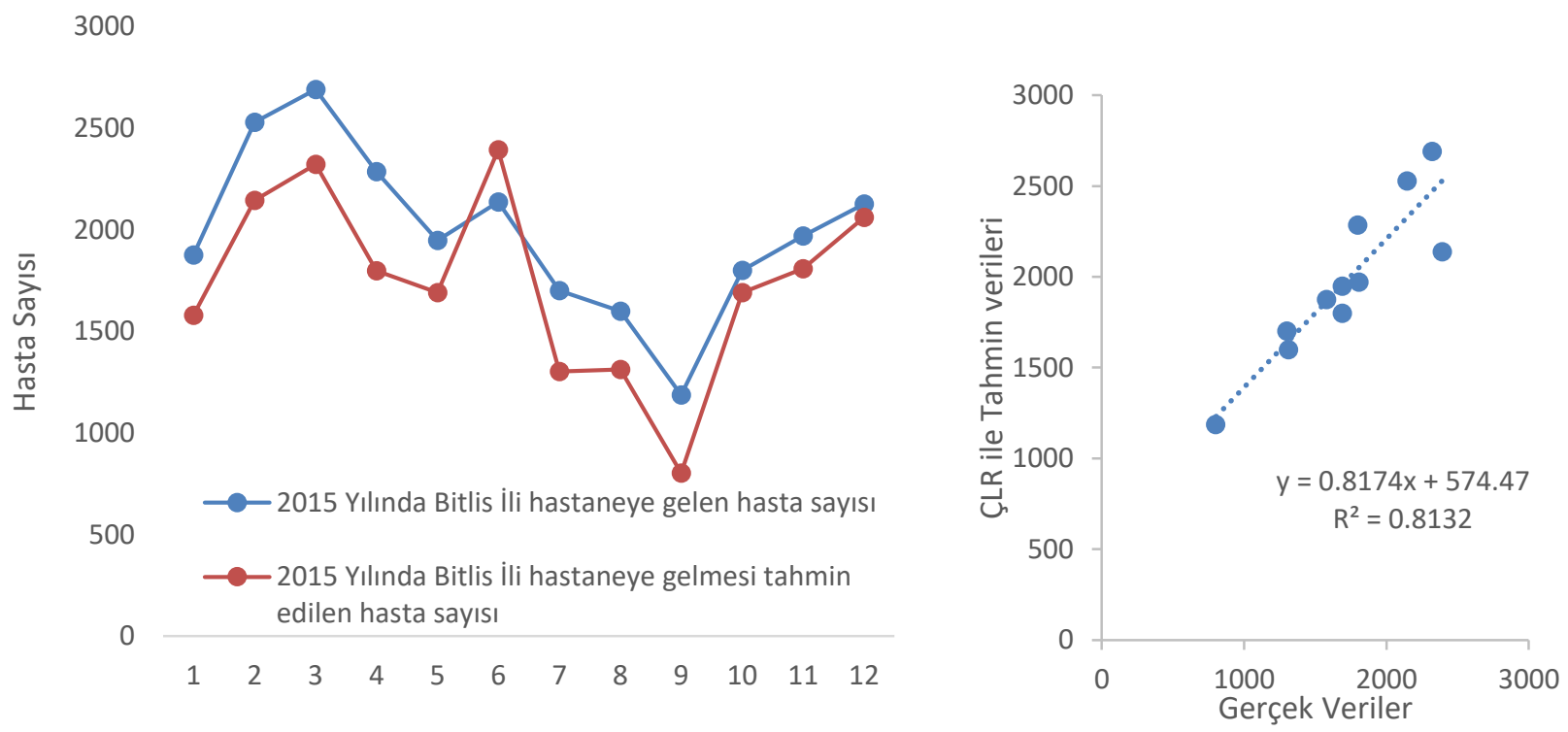

Şekil 2: 2015 yılına ait Bitlis Illi hastanelerine gelen hasta sayısı ve çoklu lineer regresyon yöntemi ile 2015 yılında hastaneye gelmesi tahmin edilen hasta sayısı

Bitlis Çevre İl Müdürlüğü’nden alınan 2015 yılına ait Bitlis İli kömür miktarları aylık kullanımı ile 2015 yılına ait Bitlis ili hastanelerine akciğer rahatsızlığı ile gelen hasta sayılarının çoklu lineer regresyon yöntemine ilişkin performans göstergesi Şekil 2'de gösterilmiştir. Bu çalışmada hasta sayıları birincil kirleticilerin verileri 2015 yılına ait olmuş olup, 2012, 2013 ve 2014 yıllarına ait hasta sayılarının verileri sadece bilgilendirme amaçlı verilmiştir. Regresyon analizine eklenmemiştir. 2015 yılı Bitlis ili hava kirliliği nedeniyle hastanelere başvuru yapan toplam hasta sayısının hava kirliliği parametreleri ile çoklu lineer regresyon ilişkisi tahmin edildiğinde aşağıdaki regresyon eşitliği elde edilmiştir (Eşitlik 1).

Toplam Hasta Sayısı $=1472.99-5014.66 \times C O+28780.9 \times N O_{x}+8297.89 \times S O_{x}-11533.8 \times P M_{10}$ 


\section{Sonuç}

Bitlis İlinde kış aylarının uzun sürmesi ayrıca yaz aylarında da sıcak su temini için kömür kullanılması yıl boyunca hava kirliliği emisyonuna neden olmaktadır. Bitlis Çevre İl Müdürlüğü’nden alınan 2015 yılına ait Bitlis İli kömür miktarları verilere göre kömür kullanımı yaklaşık 70118 tona kadar ulaşmaktadır. Kömür miktarlarına göre emisyon envanteri oluşturulurken Avrupa Çevre Ajansı (EEA 2016) tarafindan yayınlanan Emisyon Envanteri Kılavuz Kitabı'nda ve Sera Gazı Envanter Raporu'nda bulunan emisyon faktörleri değerlerinden faydalanılmıştır. Buna göre kirletici emisyon envanteri tekrar hesaplanmış ve $\left(\mathrm{R}^{2}=0.81 ; \mathrm{p}<0.05\right)$ bu bilgiler 1şı̆̆ında yerli kömür verileri sayısal analize dahil edilerek Bitlis Hava Kirliliği Emisyon Envanteri ve Sağlık Etkilerinin Çoklu Lineer Regresyonla Tahmini (Turp 2019) adlı makalenin regresyon yüzdesini düşürse de regresyon eşitliğinin varyans analizi önemli çıkmış ve \% 81 gibi yine yüksek bir determinasyon katsayısı $\left(\mathrm{R}^{2}\right)$ ile gösterilmiştir. Bitlis iline ait 2015 yılının yerli kömür tüketim verilerinin regresyon analizine eklenmeden alınan sonuç ile eklendikten sonraki sonucun determinasyon katsayısının tekrar yüksek olması, yapılan çalışmanın doğruluğunu göstermektedir.

\section{Kaynaklar}

EEA, (2015), Europen Environment Agency, https://www.eea.europa.eu/publications/air-quality-in-europe-2015, [Erişim 29 May1s 2019].

EEA, (2016), Europen Environment Agency, https://www.eea.europa.eu/publications/emep-eea-guidebook-2016, [Erişim 29 Mayıs 2019].

Sonsuz B., Kargığlu A.F., Şıpka M., Oruç M.M., Hepşen Ö., Selvi E., Mustak H., Kargı H., Karafazlığlu M., (2011), Adapazarı ilçesindeki endüstriyel kaynakl emisyonların envanterlenmesi, Lisans Bitirme Tezi, Sakarya Üniversitesi, Sakarya.

Turp S.M., Turp G.A., (2015), City of Bitlis 2014 Air Pollution Emission Inventory, Bitlis Eren Univ. J. Sci \& Technol. 5(2), 75-80.

Turp S.M., (2019), Bitlis Hava Kirliliği Emisyon Envanteri ve Sağllk Etkilerinin Çoklu Lineer Regresyonla Tahmini, Doğal Afetler ve Çevre Dergisi, 5 (1), 1-10.

URL-1, (2015), Bitlis İli 2014 Yllı Çevre Durum Raporu, T.C. Bitlis Valiliği, Bitlis Çevre ve Şehircilik İl Müdürlüğü, https://webdosya.csb.gov.tr/db/bitlis/icerikler/2014-cevre-durum-raporu-20180226094425.pdf, [Erişim 11 Temmuz 2018].

URL-2, (2016), Bitlis İli 2015 Yllı Çevre Durum Raporu, T.C. Bitlis Valiliği, Bitlis Çevre ve Şehircilik İl Müdürlüğü, https://webdosya.csb.gov.tr/db/ced/editordosya/Bitlis2015.pdf, [Erişim 29 Mayıs 2019]. 